\title{
Handgrip dynamometry, Cybex measurements and lean mass as markers of the ageing of muscle function
}

\author{
R. J. Shephard, W. Montelpare, M. Plyley, D. McCracken and R. C. Goode \\ School of Physical and Health Education, University of Toronto, Canada
}

\begin{abstract}
Isometric handgrip force, isokinetic knee flexion and extension torque, and anthropometric data were obtained on 67 older men and women (ranging in age from 45 to 75 years, mean 59.7 years). Hydrostatic and skinfold estimates of lean body mass were quite closely correlated with each other in this sample $(r=0.93)$. Handgrip force, isokinetic knee flexion and extension torque, and lean mass all decreased by $6-8 \%$ per decade over the age span examined, although in the men the loss was most marked in terms of handgrip and lean mass, whereas in the women the loss of torque in the knee muscles was dominant. Because of these differences, the handgrip data were only weakly correlated with the isokinetic strength measurements $(r=0.22)$, and the isokinetic data were more strongly related to lean body mass and body mass. The optimum equation for a field prediction of isokinetic strength in this age group (a combination of age, sex, age-sex interaction and lean body mass) has an error approaching $25 \%$, with a multiple $r^{2}$ of 0.37 , and a standard error of the estimate (s.e.e.) of $24.5 \%$. It is concluded that handgrip data and slow isokinetic torque measurements evaluate relatively independent aspects of the ageing of muscular function.
\end{abstract}

Keywords: Ageing, isometric handgrip force, isokinetic strength, knee flexion, knee extension, lean body mass

For reasons of cost and convenience, the Stoelting handgrip dynamometer (Type TKK Model 1201 Dynamometer, C. H. Stoelting, Chicago, Illinois, USA) has been widely used in field surveys of both children and adults ${ }^{1}$. Some observers have found correlations as high as 0.80 between such data and overall measures of isometric strength ${ }^{2,3}$ or isokinetic torque ${ }^{4}$. However, the muscles involved in the isometric gripping movement are relatively small, and it seems likely that the ability to generalize from such findings might be reduced in an older population where a selective loss of lean tissue is likely to have occurred. Accordingly, we have examined the relationships between isometric handgrip force and isokinetic measurements of knee extension and flexion torque at three slow speeds of rotation,

Address for correspondence: Professor Roy J. Shephard, Director, School of Physical and Health Education, 320 Huron Street,

Toronto, Ontario M5S 1A1, Canada

(C) 1991 Butterworth-Heinemann Ltd

0306-3674/91/040204-05 comparing the rate of ageing in both datasets with estimates of overall lean mass derived from hydrostatic and skinfold estimates of body fat.

\section{Methods}

\section{Subjects and experimental plan}

The subjects were 33 women and 34 men aged 45-74 years, all clinically healthy and only moderately active, but nevertheless volunteers for an experimental programme that included subsequent assignment in random fashion to weekly light exercise classes, classes in health education, or a control group. Recruits were drawn from the university community in accordance with a plan approved by the University Committee on Human Experimentation. Measurements of isometric handgrip force, isokinetic knee extension and knee flexion torque, and body composition were completed before beginning the programme (Table 1).

\section{Isometric handgrip force}

All measurements were made with a Stoelting handgrip dynamometer, individually adjusted for the size of the subject's handgrip. Two definitive measurements were made on each hand, the peak force (newtons) being recorded in each case.

\section{Isokinetic torque}

All measurements were made with a Cybex II isokinetic dynamometer (Lumex Corporation, New York, USA), using the right leg. After careful alignment of the knee joint with the axis of the apparatus, three different angular velocities of knee extension and knee flexion were presented to the subjects in a randomized order: 18,30 and $60^{\circ} \mathrm{s}^{-1}$ $\left(0.32-1.05 \mathrm{rad} \mathrm{s}^{-1}\right)$. Three measurements were made at each of the three angular velocities commencing with the knee flexed at $90^{\circ}$. To obtain readings free of distortion, the damping selection switch was set to zero and torques were recorded $30^{\circ}$ after the initiation of contraction. Forces were thus recorded at an angle of $60^{\circ}$ from the vertical during extension, while during flexion forces were recorded at an angle of $120^{\circ}$. As can be seen from Figure 1, this approach allows the recording of torque without application of 
Table 1. Physical characteristics of subjects

\begin{tabular}{|c|c|c|c|}
\hline Variable & Women $(n=33) \dagger$ & Men $(n=34) \dagger$ & Total $(n=67) \dagger$ \\
\hline $\begin{array}{l}\text { Age (years) } \\
\text { Height }(\mathrm{cm}) \\
\text { Body mass }(\mathrm{kg}) \\
\text { Skinfolds }(<4, \mathrm{~mm}) \\
\text { Hydrostatic body fat }(\%) \\
\text { Lean body mass }(\mathrm{kg})\end{array}$ & $\begin{array}{c}61.5(10.7) \\
160.1(7.3) \\
65.3(11.4) \\
112.1(35.6) \\
39.3(7.7) \\
38.4(5.7)\end{array}$ & $\begin{array}{c}57.5(8.5) \\
173.8(5.9) \\
74.7(11.9) \\
77.7(23.6) \\
27.8(6.0) \\
55.0(7.2)\end{array}$ & $\begin{array}{c}59.7(9.8) \\
167.3(42.8) \\
69.6(12.5) \\
94.1(34.4) \\
33.4(9.0) \\
47.0(10.6)\end{array}$ \\
\hline $\begin{array}{l}\text { Handgrip force } \\
R(N) \\
L(N) \\
R+L(N)\end{array}$ & $\begin{array}{l}325(116) \\
297(91) \\
622(205)\end{array}$ & $\begin{array}{l}485(89)^{* * *} \\
451(82)^{* * *} \\
936(167)^{* * *}\end{array}$ & $\begin{array}{l}404(131) \\
372(116) \\
776(244)\end{array}$ \\
\hline $\begin{array}{l}\text { Isokinetic knee flexion torque } \\
18^{\circ} \mathrm{s}^{-1}(\mathrm{Nm}) \\
30^{\circ} \mathrm{s}^{-1}(\mathrm{Nm}) \\
60^{\circ} \mathrm{s}^{-1}(\mathrm{Nm})\end{array}$ & $\begin{array}{l}63.3(17.5) \\
63.1(18.4) \\
60.8(19.9)\end{array}$ & $\begin{array}{l}75.2(23.7)^{*} \\
79.7(24.1)^{* *} \\
76.8(23.2)^{* *}\end{array}$ & $\begin{array}{l}69.1(21.5) \\
71.3(22.8) \\
68.7(22.9)\end{array}$ \\
\hline $\begin{array}{l}\text { Isokinetic knee extension torque } \\
\qquad 8^{\circ} \mathrm{s}^{-1}(\mathrm{Nm}) \\
30^{\circ} \mathrm{s}^{-1}(\mathrm{Nm}) \\
60^{\circ} \mathrm{s}^{-1}(\mathrm{Nm})\end{array}$ & $\begin{array}{l}50.0(13.5) \\
49.5(13.6) \\
48.3(13.7)\end{array}$ & $\begin{array}{l}63.2(20.1)^{* *} \\
64.5(19.9)^{* * *} \\
62.5(19.5)^{* * *}\end{array}$ & $\begin{array}{l}56.5(18.2) \\
56.9(18.5) \\
55.3(18.1)\end{array}$ \\
\hline
\end{tabular}

Values are mean(s.d.)

+ Because of missing data, some totals are marginally smaller

Significance of sex differences: ${ }^{*} P<0.05 ;^{* *} P<0.01 ;{ }^{* * *} P<0.001$

external damping. At the slower speeds, the contraction was sustained for longer before measuring the torque. This method of assessment thus had the interesting effect of equalizing the recorded torques relative to speed of rotation over the range $18-60^{\circ} \mathrm{s}^{-1}$. No gravitational correction was applied to the torque data, because methods of applying such corrections remain controversial. Gravitational effects can be important during light contractions at low angular velocities ${ }^{5}$, adding major distortions to the early part of the torque record. However, such effects are much smaller under the conditions adopted in the present experiment (maximal contractions, with measurement late in the contraction cycle). The likely effect would be some overestimate of extensor torque $(<25 \%)$ and some underestimate of flexor torque $(<25 \%)$; given that the subjects were relatively homogeneous, such systematic errors would also be relatively constant from one person to another.

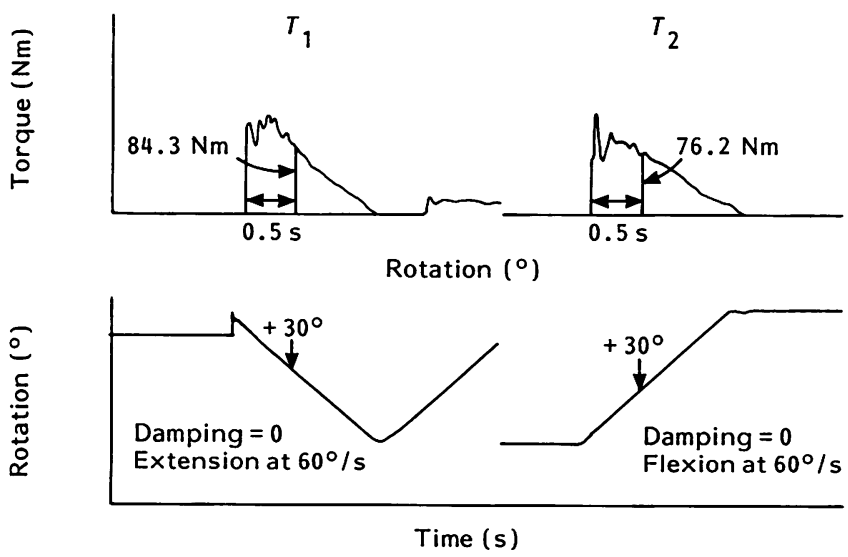

Figure 1. The recording of isokinetic torque $30^{\circ}$ after the initiation of knee flexion or extension. In both cases, the force can be recorded without interference from oscillations at this stage. Data for 60 -year-old man with isokinetic device recording flexion or extension force at $60^{\circ} \mathrm{s}^{-1}$

\section{Body composition}

Height and body mass were recorded by standard anthropometric techniques ${ }^{6}$. Body density was determined by hydrostatic weighing, residual volume being determined by nitrogen dilution, and the percentage of body fat was predicted according to the equations of Siri ${ }^{7}$. Biceps, triceps, subscapular and suprailiac skinfold thicknesses were also measured on the right side of the body, using Lange skinfold calipers, and a second estimate of body density and thus body fat was made using the equations of Durnin and Womersley ${ }^{8}$. The lean body mass was then calculated from total body mass and from each of the two estimates of percentage body fat.

\section{Statistical analysis}

The statistical analysis included descriptive variables (mean(s.d.)), the correlation of individual variables with isometric force, isokinetic torque and lean body mass, and a step-down multiple regression for the prediction of isokinetic torque eliminating all regression coefficients with a $P$ value $>0.1$.

\section{Results and discussion \\ Descriptive variables}

The mean age of the sample was a little under 60 years. Both women and men were a little taller than subjects of comparable age who were tested in the Canada Fitness Survey (CFS), the mean heights being 157.5 and $171.0 \mathrm{~cm}$, respectively ${ }^{1,9}$. This probably reflects the fact that they were drawn from a group of somewhat above average socioeconomic status. The body mass of the women was close to the CFS age-matched mean of $64.1 \mathrm{~kg}$, while the men were a little lighter than the CFS sample (mean $77.4 \mathrm{~kg}$ ).

It is recognized that the hydrostatic weighing technique tends to be compromised by osteoporosis 
in older individuals, while the validity of skinfold estimates of body fat deteriorates because of alterations in the proportions of deep and superficial fat ${ }^{10}$. Nevertheless, in the present sample, the two techniques gave similar results (respective mean(s.d.) percentage body fat $33.4(9.0)$ and $36.0(9.0)$, coefficient of correlation 0.78 ; mean lean body mass $44.5(10.2)$ and $47.0(10.6) \mathrm{kg}$, coefficient of correlation 0.93).

Both the summated skinfolds and the estimates of percentage body fat were substantially above the CFS levels (CFS readings for subjects over 60 years: women, $67.2 \mathrm{~mm}, 29.9 \%$ fat; men $50.8 \mathrm{~mm}, 23.2 \%$ fat). This confirms individual comments that one factor motivating volunteers for the study was a wish to reduce body fat.

Given a normal or low normal body mass, and a high percentage of body fat, it is plain that the sample had a less than average lean body mass for their age. Nevertheless, the isometric handgrip forces exceeded the CFS means of $425 \mathrm{~N}$ in the men and $253 \mathrm{~N}$ in the women ${ }^{1}$.

Because of the measuring technique used, isokinetic torque values were of the same general order at all three speeds, with a difference of some $20 \%$ between scores for the men and the women. A similar difference between flexion and extension scores must be interpreted with caution because of the gravitational effects noted under methodology. Readings at $60^{\circ} \mathrm{s}^{-1}$ were somewhat smaller than the 89 and $61 \mathrm{Nm}$ reported by Laforest et al. ${ }^{11}$ for extension and flexion movements, respectively, in sedentary 65year-old men and women.

\section{Individual correlations}

The similarity of results for the three flexion and three extension torques speaks against any substantial distortion of results by gravitational effects. Detailed results are considered simply for the movement of flexion at $60^{\circ} \mathrm{s}^{-1}$ (Table 2). As might be expected from ergonomic experience with younger adults ${ }^{12,13}$, the largest coefficients of correlation were with lean body mass and total body mass. Both of these measurements showed substantially larger coefficients for isometric handgrip force $(r=0.70,0.54)$ than for isokinetic flexion torque $(r=0.40,0.36)$.

Since estimates of lean body mass were obtained by both hydrostatic weighing and by skinfold measurement, it was possible to assess the validity of the two estimates relative to handgrip force and isokinetic torque measurements. Coefficients of correlation were of a similar order for hydrostatic $(r=0.71,0.70)$ and for skinfold $(r=0.31,0.40)$ estimates. The hydrostatic estimate has been used in subsequent calculations.

\section{Prediction of isokinetic torque}

Data for the prediction of isokinetic torque scores were entered into multiple regression equations of the type:

$$
\begin{aligned}
\text { Cybex torque }= & a(\text { sex })+b(\text { lean mass })+c(\text { summed } \\
& \text { grip })+d
\end{aligned}
$$

Table 2. Individual variables and products significantly correlated with isokinetic flexion torque at $60^{\circ} \mathrm{s}^{-1}$

\begin{tabular}{lcc}
\hline Variable & $\begin{array}{c}\text { Coefficient of } \\
\text { correlation }\end{array}$ & $P$ \\
\hline Height & 0.26 & 0.037 \\
Body mass & 0.36 & 0.007 \\
Hydrostatic body fat & -0.20 & 0.088 \\
Lean body mass & 0.40 & 0.003 \\
Sum of grip forces & 0.22 & 0.067 \\
Left grip force & 0.22 & 0.065 \\
Right grip force & 0.22 & 0.073 \\
Age & -0.25 & 0.042 \\
Age & -0.25 & 0.043 \\
Sex & 0.23 & 0.056 \\
Sex/skinfolds & 0.35 & 0.009 \\
Sex/body mass & 0.31 & 0.018 \\
Sex/lean mass & 0.30 & 0.019 \\
Sex/right + left grip & 0.23 & 0.063 \\
Sex/height & 0.24 & 0.050 \\
Age/body fat & -0.29 & 0.022 \\
Age/lean mass & 0.28 & 0.029 \\
\hline
\end{tabular}

using all of the measured variables as initial entry data. An example of the process for isokinetic flexion at $60^{\circ} \mathrm{s}^{-1}$ is given in Table 3 , and the general similarity of responses under the other conditions of measurement is illustrated in Table 4.

The primary variables for the prediction of isokinetic force at $60^{\circ} \mathrm{s}^{-1}$ were, in order of statistical significance, the sex of the individual $(F=1, M=2)$, the product of sex and age, the age, and the lean body mass. When these variables had been entered, the remaining items were no longer statistically significant, the equation becoming:

$$
\begin{aligned}
\text { Torque }(\mathrm{Nm})= & -122.6(\mathrm{sex})-2.69 \text { (age) }+1.91 \\
& \text { (age-sex) }+1.17 \text { (lean mass) }+187.9 \\
& \text { (s.e.e. 16.8) }
\end{aligned}
$$

The multiple correlation coefficient was 0.61 , showing that these variables together accounted for some $37 \%$ of the variance in the isokinetic data, the standard error of the estimate amounting to $24.5 \%$. It is perhaps worth stressing that the prediction is only a little more precise than that derived from sex, age, age-sex interaction and total body mass:

$$
\begin{aligned}
\text { Torque }(\mathrm{Nm})= & -106.5(\text { sex })-2.92(\text { age })+1.89 \\
& \text { (age-sex) }+0.51(\text { mass })+196.5(r= \\
& 0.59, \text { s.e.e 16.96, 24.7\%) }
\end{aligned}
$$

Table 3. Multiple regression equation for prediction of isokinetic flexion torque at $60^{\circ} \mathrm{s}^{-1}$

\begin{tabular}{lcc}
\hline Variable & $\beta$-weight* & Significance \\
\hline Sex $(\mathrm{F}=1, \mathrm{M}=2)$ & $-122.6(33.6)$ & $<0.0007$ \\
Sex-age & $1.91(0.53)$ & $<0.0009$ \\
Age (years) & $-2.69(0.76)$ & $<0.0010$ \\
Lean mass $(\mathrm{kg})$ & $1.17(0.39)$ & $<0.005$ \\
Constant & $187.9(47.0)$ & $<0.0003$ \\
\hline
\end{tabular}

${ }^{*}$ Values are mean(s.d.); s.e.e. 16.8, Multiple $r=0.61, r^{2}=0.37$ Variables rejected: age ${ }^{2}$, height, body mass, left handgrip force, right handgrip force, summed grip force, skinfolds, body fat 
Ageing of muscle function: R. J. Shephard et al.

Table 4. Statistical significance of multiple regression analyses for prediction of isokinetic flexion $(F)$ and extension (E) torque

\begin{tabular}{|c|c|c|c|c|c|c|}
\hline \multirow[t]{2}{*}{ Variable } & \multicolumn{2}{|c|}{$18^{\circ} \mathrm{s}^{-1}$} & \multicolumn{2}{|c|}{$30^{\circ} \mathrm{s}^{-1}$} & \multicolumn{2}{|c|}{$60^{\circ} \mathrm{s}^{-1}$} \\
\hline & $F$ & $E$ & $F$ & $E$ & $F$ & $E$ \\
\hline $\begin{array}{l}\text { Sex } \\
\text { Age } \\
\text { Age-sex } \\
\text { Lean mass } \\
\text { Grip sum } \\
\text { Grip left }\end{array}$ & $\begin{array}{c}-0.050 \\
-0.077 \\
+0.076 \\
+0.025 \\
\text { n.s. } \\
\text { n.s. }\end{array}$ & $\begin{array}{l}\text { n.s. } \\
-0.011 \\
+0.087 \\
\text { n.s. } \\
\text { n.s. } \\
\text { n.s. }\end{array}$ & $\begin{array}{c}-0.019 \\
-0.025 \\
+0.028 \\
+0.008 \\
\text { n.s. } \\
\text { n.s. }\end{array}$ & $\begin{array}{l}\text { n.s. } \\
-0.005 \\
+0.018 \\
\text { n.s. } \\
\text { n.s. } \\
\text { n.s. }\end{array}$ & $\begin{array}{c}-0.0007 \\
-0.0010 \\
+0.0009 \\
+0.0047 \\
\text { n.s. } \\
\text { n.s. }\end{array}$ & $\begin{array}{l}-0.056 \\
-0.004 \\
+0.025 \\
+0.160 \\
+0.059 \\
-0.075\end{array}$ \\
\hline$r^{2}$ & 0.19 & 0.12 & 0.28 & 0.18 & 0.37 & 0.33 \\
\hline s.e.e. & 18.7 & 14.8 & 17.4 & 14.7 & 16.8 & 13.3 \\
\hline
\end{tabular}

n.s. not significant

Kofsky et al. ${ }^{4}$ have explored the possibility of making field predictions of isokinetic strength in patients in wheelchairs. They were able to achieve a correlation coefficient of 0.82 between isometric and isokinetic data, the standard error of the estimate being $12.9 \%$; this was partly because of a larger spread in their data, in part because higher speeds of movement were used, and in part because they measured the maximum isometric force in six muscle groups.

\section{Effects of age}

Given that there is some loss of lean tissue with ageing (about 2.5\% decrease per decade in the present sample), a change in gravitational correction could have increased the uncorrected flexor torque by up to $0.6 \%$ per decade, with an opposite effect in extension. When considered in isolation, age was negatively related to the uncorrected isokinetic force in the women $(r=-0.58, P=0.0013)$, but had no significant influence on data in the men $(r=0.24$, $P=0.25)$; this presumably reflects the fact that the men reported higher levels of daily physical activity than the women. The mean(s.e.m.) loss of torque for the sample as a whole was $17.7(8.1) \%$ over the age range $45-75$ years $(r=-0.29, P=0.03)$, a much larger change than could arise from changes in gravitational effects. The pooled data for the men and women showed significant linear and quadratic relationships of age to isokinetic force. The sex of the subject also influenced isokinetic force, most obviously as cross products with skinfolds, body mass and lean mass, implying that each of the latter variables had a different influence on isokinetic strength in the two sexes. Likewise, age/body fat and age/lean mass had significant cross products, suggesting that the influence of lean mass upon isokinetic force varied with age (Table 2).

The summed handgrip force had a significant negative relationship to age in the men $(P<0.0005)$, but not in the women, the slope for the group as a whole being $-6.67(3.53) \mathrm{N}_{\text {year }}{ }^{-1}$, corresponding to a loss of $22.8 \%$ over the age span $45-75$ years.

The loss of lean body mass was also significant in the men $(P=0.02)$ but not in the women, the mean effect for the group as a whole being a loss of
$0.45(0.15) \mathrm{kg} \mathrm{year}^{-1}$, a loss of $26.2 \%$ over the age span 45-75 years.

There is little argument that the muscles generally become weaker with ageing ${ }^{1,14-21}$, although biopsy studies have generally been on the leg muscles. It is less certain that the muscles involved in an isometric handgrip age at the same rate as the isokinetic function of the leg; indeed, our data suggest a sex difference in the ageing of these two datasets, with the handgrip force running more in parallel with the loss of lean tissue. At all of the speeds of rotation tested, ageing led to a linear decline of isokinetic force at the knee in the female subjects; moreover, after allowance for the linear age term, there was no significant quadratic term over the age range examined (Table 4).

Averaging across the sexes, the loss of isokinetic torque amounted to about $5.9 \%$ per decade, a loss that is similar to the $6 \%$ per decade reported by Laforest $e$ e $a .^{10}$ at $60^{\circ} \mathrm{s}^{-1}$; at the same time there was a $7.6 \%$ per decade loss of handgrip force and an $8.7 \%$ loss of lean body mass. Even if further ageing does not introduce a quadratic term, such a rate of loss seems likely to have an important impact upon function in later old age, pointing to the need for training programmes to maintain and restore muscle strength.

\section{Sex differences}

The effects of sex were shown in our sample through a negative sex coefficient and a positive sex-age interaction (Table 3), implying that the difference in isokinetic force between men and women increased with age. The age-related decline of torque was due entirely to the female subjects.

These findings contrast with those of Laforest et al. ${ }^{11}$, who found no age-sex interaction when comparing the isokinetic strength of young (25-30year-old) and elderly (65-year-old) men and women. Like Laforest et al. ${ }^{11}$, we used a relatively small non-random sample, and the difference of results is likely to be because of recruiting bias. Laforest et al. ${ }^{11}$ attempted to minimize sex differences of activity patterns by testing continuing tennis players and continuing sedentary subjects of each sex. In our 
sample, the older male recruits had a moderate level of habitual activity, and a number were interested in restoring their cardiorespiratory fitness by jogging, whereas the women were less active and were interested primarily in the control of body fat.

\section{Generality of measures of muscle function}

Lean body mass was positively correlated with isokinetic force, and in five of the six analyses there was no independent contribution from isometric handgrip force once lean mass had been included in the prediction equation. Indeed, even the simple correlation between isometric handgrip force and isokinetic strength was relatively weak. It thus appears that the two tests measure different attributes in this age group.

The isometric handgrip force has a larger correlation with lean mass than does the knee torque, and it may thus be a more generalizable measure of residual muscle function. However, whether generalizable or not, handgrip force remains very important to the activities of daily living in old age. Lean body mass provides a simpler and more valid field measure of isokinetic knee torque than does the estimation of maximal isometric handgrip force. However, even the optimal prediction equation based upon age, sex and lean mass has an error of almost $25 \%$ at slow speeds of contraction.

\section{Conclusions}

In the present sample of relatively sedentary older men and women, muscle function declined by $6-8 \%$ per decade. There is only a limited correlation between losses of isometric handgrip force (seen mainly in the men) and the isokinetic torque of knee flexion and extension (seen mainly in the women). Although the isometric handgrip measurements are relatively easy to make, they measure a different attribute than isokinetic torque. Rough estimates of the latter can be based upon age, sex and lean body mass, but the error of such predictions is likely to approach $25 \%$ in older individuals.

\section{References}

1 Shephard RJ. Fitness of a Nation. Basel: Karger, 1986.

2 Clarke $\mathrm{HH}$. Toward a better understanding of muscular strength. Phys Fitness Res Digest 1973; 3: 1-20.

3 Jackson A, Watkins M, Patton RW. A factor analysis of twelve selected maximal isotonic strength performances on the Universal Gym. Med Sci Sports Exerc 1980; 12: $274-7$.

4 Kofsky P, Davis GM, Jackson RW, Keene GCR, Shephard RJ. Field testing - assessment of physical fitness of disabled adults. Eur J Appl Physiol 1983; 51: 109-20.

5 Winter DA, Wells RP, Orr GW. Errors in the use of isokinetic dynamometers. Eur J Appl Physiol 1981; 46: 397-408.

6 Weiner JS, Lourie JA. Practical Human Biology. New York: Academic Press, 1981.

7 Siri WE. The gross composition of the body. In: Laurence JH, Tobias CA, eds. Advances in Biological and Medical Physics. London: Academic Press, 1956.

8 Durnin JVGA, Womersley J. Body fat measured from total body density and its estimation from measurements of skinfold thickness. Br J Nutr 1974; 32: 77-97.

9 Canada Fitness Survey. Fitness and Lifestyle in Canada. Ottawa: Fitness and Amateur Sport, 1983.

10 Shephard RJ. Body Composition in Biological Anthropology. London: Cambridge University Press, 1991.

11 Laforest S, St-Pierre DMM, Cyr J, Gayton D. Effects of age and regular exercise on muscle strength and endurance. Eur $J$ Appl Physiol 1990; 60: 104-11.

12 Nottrodt JW, Celentano EJ. Use of validity measures in the selection of physical screening tests. In: Attwood DA, McCann C, eds. Proceedings of the 1984 International Conference on Occupational Ergonomics. Toronto: Human Factors Association of Canada, 1984.

13 Wyndham $\mathrm{CH}$. An examination of the methods of physical classification of African labourers for manual work. $S$ Afr Med J 1966; 40: 275-8.

14 Aniansson A, Grimby G, Hedberg M, Rundgren A, Sperling L. Muscle function in old age. Scand J Rehabil Med 1978; 6 (Suppl): 43-9.

15 Davies CTM, White MJ. Contractile properties of the elderly human triceps surae. Gerontology 1983; 29: 19-25.

16 Larsson L, Grimby G, Karlsson J. Muscle strength and speed of movement in relation to age and muscle morphology. $J$ Appl Physiol 1979; 46: 451-6.

17 Pearson MB, Bassey EJ, Bendall MJ. Muscle strength and anthropometric indices in elderly men and women. Age Ageing 1985; 14: 49-54.

18 Aniansson A, Hedberg M, Henning GB, Grimby G. Muscle morphology, enzymatic activity and muscle strength in elderly men: a follow-up study. Muscle Nerve 1986; 9: 585-91.

19 Davies CTM, Thomas DO, White MJ. Mechanical properties of young and elderly human muscle. Acta Med Scand 1986; 711(Suppl): 219-26.

20 Fiatarone MA, Marks EC, Ryan ND, Meredith CN, Lipsitz LA, Evans WJ. High intensity strength training of nonagenarians. J Am Med Assoc 1990; 263: 3029-34.

21 Rikli R, Busch S. Motor performance of women as a function of age and physical activity level. J Gerontol 1986; 41: 645-9. 